\title{
Smart Mirror Using Raspberry Pi
}

\author{
Prof. V. E. Pawar ${ }^{1}$, Pooja Sisal ${ }^{2}$, NeelamSatpute $^{3}$ \\ BharatiVidyapeeth College Of Engineering, Sector-7,C.B.D, Belpada, Navi Mumbai-400614,India.
}

\section{Abstract:}

Intelligent mirrors, which continue the works today and will take its place in the future technology, provide both mirror and computer aided information services to its users. Thanks to the microcontroller cards on board, these systems, which can connect to the internet and take data from the internet, can show this information on the places located on the mirror. In the scope of the study, the developed intelligent mirror system includes the weather information, time and location information, current event information, user information, and camera image taken from web services using Raspberry Pi 3 microcontroller card. Some equipment can be controlled by voice commands via the microphone on the smart mirror.

A smart mirror displays applications so that you can check the weather, local news, etc. while you are getting ready in the morning. The mirror will do the thinking for the user in a smart way. This smart mirror aims to reduce and possibly eliminate the need for the user to make time in their daily morning or nightly routine to check their PC, tablet, or smartphone for the information they need. The making of this smart mirror includes a micro-controller called Raspberry Pi which will act as a brain of the interactive system. The micro-controller will be powered using python scripts for mirror software as well as personal assistant. For making of this personal assistant an Amazon Web Services (AWS) account is required. Using the AWS, the Alexa function and alexa skills using skill kit will be created. Once the function is setup, the function can be accessed using a command line after the software is installed. An 18" LED Monitor will be placed below an acrylic two-way mirror sheet and the model will be placed in a wooden frame.We'll build a separate personal assistance that will be able to recognize and perform speech to text operations. The personal assistance is named ALEXA. There is a huge scope for this project and AI is much needed today.

\section{Keywords -- Raspberry Pi, node.js, python, JavaScript}

\section{INTRODUCTION}

Efficiency and productivity are two qualities that are increasingly establishing their dominance as keywords companies are using to market their products. The fact that their product can multitask or increase productivity better than the competition has become a real selling point. This is due to the fact that effective time management is an essential factor in increasing production of day-to-day life. The best time management strategies involve being able to find time where there was no time before. Integration of technology into people's daily lives has made that time management possible. The use of products such as tablets, PCs, and smartphones have given people access to the tools needed to be productive. However, though successful technological products have been used to increase productivity, it has done its fair share to stifle it as well. The use of technology has become another task on everyone's daily todo list. Technology should mold to our schedule, not the other way around.

That is where the smart mirror idea originated. The smart mirror idea aimed to integrate technology seamlessly into people's lives by putting it where everyone's routine eventually collides, the bathroom. The goal of the smart mirror is to increase a user's productivity by saving them time. The smart mirror provides a near effortless experience that allows the user to just walk up and be greeted with information 


\section{LITERATURE SURVEY}

\begin{tabular}{|l|l|l|l|l|}
\hline Parameters & Paper 1: Fatma Ok & Paper 2: Murat Can & Paper 3: HakanUcgun & Paper 4: UgurYugec \\
\hline Technology & Raspberry Pi 3 & Raspberry Pi 2 & Pineapple Pi & Raspberry Pi 3 \\
\hline Language & Python & Java & Python & GoLang \\
\hline Display applications & $\begin{array}{l}\text { Weather, news, date, } \\
\text { time, temperature }\end{array}$ & $\begin{array}{l}\text { Weather, news, in-built } \\
\text { applications }\end{array}$ & $\begin{array}{l}\text { Weather, news, things to } \\
\text { do reminder, temperature }\end{array}$ & $\begin{array}{l}\text { Weather, news, in-built } \\
\text { alarm, date, time }\end{array}$ \\
\hline Personal assistant & Yes & Yes & No & No \\
\hline
\end{tabular}

\section{SYSTEM ARCHITECTURE}

\section{Raspberry Pi 3}

The Raspberry $\mathrm{Pi}$ is a small, credit cardsized computer that powers the whole thing, displaying the Magic Mirror interface and running Alexa, the voice-control system. The Raspberry $\mathrm{Pi} 3$ is a single board computer which features a quad core ARM cortex A-5 processor, with the capability to run Linux based operating systems. The Raspberry Pi 3 has an integrated LAN port which can be used to connect to the internet. It also comes with double row GPIO (General Purpose Input Output) pins which can be used for interfacing it with a variety of I/O devices. We will be installing debianbased Raspbian OS Jesse on the Raspberry Pi and download and install node.js for the packages.

\section{The two-way mirror}

The two-way mirror is made of acrylic and sits flush over the monitor, allowing the graphics on the monitor to come through while maintaining a mirror effect. I ordered my mirror through AmoghAluminium. The thicker mirror option (3/16") to prevent a "funhouse mirror" effect.

\section{The Monitor Display}

An LED monitor for minimal power consumption, maximum crispness, and to prevent mirror glow at night.The required information for the user will be displayed on the LED monitor.

\section{The box/frame}

The box/frame houses all the components, including the microphone, and looks pretty.

\section{Speakers for Output}

A $3.5 \mathrm{~mm}$ jack speaker will be required for speech output of the personal assistant 


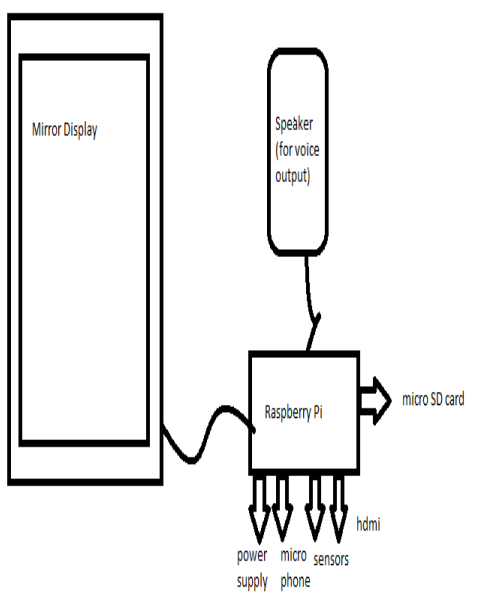

\section{PROPOSED SYSTEM}

The mirror will do the thinking for the user with the help of an in-built personal assistant. It will update with the user's calendar schedule, to-do lists, news, and weather etc. The information wouldn't be thrown in the user's face, but unobtrusively displayed on the edges of the mirror to still allow use of the actual mirror.

The use of personal assistant will keep things simple and easy to use. No keyboards to try to keep dry and clean. The personal assistant will also allow the user to still use the mirror despite their hands are wet or dirty. The mirror provides common information most people check their smartphones or tablets for, such as weather, news, Twitter and schedules.

This allows the users to read, think, and plan their day while getting ready in the morning or night.

Finally, the mirror must be smart enough to protect itself from the wet and humid conditions. It will feature a humidity protection system where itwill monitor the temperature and humidity levels near the hardware.

\section{CONCLUSION}

The goals of the smart mirror were to aim to reduce time needed in a user's daily routine and provide a merger of user and technology that becomes an enhancement, not a new burden. The functionality must meet these descriptions in the design. The smart mirror did the thinking for the user with intelligent, commonly used applications. Apps like their calendar, music, news, Twitter, to-do lists, and weather will be available. The apps were unobtrusively displayed on the screen, hidden by the two-way mirror, as to look like a seamless experience. The user didn't even have to worry about turning on and off the system because the mirror will detect motion and do the work for them. A good project can't be produced without proper research first. Similar projects and products were analyzed for similarities, improvements, and flaws. The group researched each important parts of the mirror system such as the gesture control, voice control, MCUs, and others. Once enough information was collected about specifications and prices, strategic components were selected to be part of the project from both a hardware and software perspective.

\section{REFERENCE}

[1]https://www.magicmirrorcentral.com/bes t-glass-smart-mirrorproject/

[2] https://www.quora.com/Is-starting-asmart-mirror-company-agood-idea

[3] Anonymous, "JavaScript Tutorial", http://www.w3schools.com/js/

[4] Anonymous, "Node.js - NPM" https://www.tutorialspoint.com/nodejs/ nodejs_npm.htm 
[5] Anonymous, "Yeoju Smart Mirror by Ian Seyler"

http://imwm.org/yeoju-smart-mirror-byian-seyler/

[6] Anonymous, " Current weather and forecasts in your city"https://openweathermap.org/

[7] Anonymous, "Pushbullet", https://www.pushbullet.com/, Son

[8] GitHub, "MagicMirror", https://github/MichMich/MagicMirror 